\title{
LA MISIÓN DE LA IGLESIA EN EL MARCO DEL GRAN
} [The Mission of the Church in the Great Controversy Framework]

\author{
Christian Varela \\ chrav2009@gmail.com \\ Hasenkamp, Entre Ríos \\ Unión Argentina, Argentina \\ Joel Iparraguirre \\ joeliparraguirre@upeu.edu.pe \\ Facultad de Teología \\ Universidad Peruana Unión \\ Lima, Perú
}

Recibido: 05/01/2019 Aceptado: 30/01/2019

\section{Resumen}

La misión de Dios en el contexto del discipulado es el imperativo para los creyentes de hoy. Diversos enfoques han propuestos perspectivas variadas para la misión de la iglesia. El gran conflicto entre Cristo y Satanás esclarece la naturaleza de la misión comisionada a su pueblo de todos los tiempos. Por tanto, este estudio analiza la misión de la iglesia en el marco del gran conflicto y sus respectivas implicancias misionológicas.

Palabras clave: Dios, misión, discipulado, iglesia, gran conflicto

\begin{abstract}
God's mission in the context of discipleship is an imperative for believers today. Several approaches have proposed mixed perspectives for the Church's mission. The great controversy between Christ and Satan clarifies the nature of the mission commissioned to His people of all times. Therefore, this study analyzes the mission of the church in the context of the great controversy and their respective missiological implications.
\end{abstract}

Keywords: God, mission, discipleship, church, great controversy 


\section{INTRODUCCIÓN}

La missio Dei en el contexto del discipulado es el mayor desafío de la iglesia en medio de una sociedad materialista, secularizada y pluralista. Mucho se ha escrito sobre la misión en cuanto a su naturaleza y metodología, pero ¿es importante tener una cosmovisión definida para hacer una teología de la misión? ${ }^{1}$ ¿Cuál debería ser? Wagner Kuhn afirma que “la misión de la Iglesia Adventista del Séptimo Día se lleva adelante en el contexto del gran conflicto y la pronta venida de Jesús" ${ }^{2}$ Con esto en mente, aquí se propone un acercamiento a una misionología en el marco de la creencia del gran conflicto, tema central para la Iglesia Adventista del Séptimo Día (IASD). ${ }^{3}$ Dada la amplitud de este asunto, la investigación se delimitará a los aspectos más sobresalientes expresados en las Escrituras y se realizarán sugerencias para la praxis de la iglesia.

\section{LA COSMOVISIÓN DEL GRAN CONFLICTO ${ }^{4}$}

La octava creencia fundamental de la IASD expresa la realidad del conflicto cósmico entre Cristo y Satanás. ${ }^{5}$ A continuación, se repasarán brevemente algunos conceptos claves.

1Fernando Canale se pregunta: “¿Es el tema de la cosmovisión tan importante para la vida y la misión de la iglesia de hoy?". "La cosmovisión teológica y su influencia sobre la Iglesia Adventista del Séptimo Día", Enfoques 11, no. 1-2 (1999): 101; ídem, "El mensaje y la misión del remanente", Ed. Angel Manuel Rodríguez (Buenos Aires: ACES, 2015): 254-277.

2Wagner Kuhn, "Adventist Theological-Missiology: Contextualization in Mission", Journal of the Adventist Theological Society, 27, no. 1-2 (2016): 180, En adelante JATS. Larry L. Lichtenwalter, "Worldview Transformation and Mission: Narrative, Theology, and Ritual in John's Apocalypse", JATS 21, no. 1-2 (2010): 211.

${ }^{3}$ Herbert E. Douglass, "The Great Controversy Theme: What it means to Adventists", Ministry (Nov.-Dic., 2000), 5, afirmó lo siguiente con respecto al gran conflicto: "Para los Adventistas del Séptimo Día, el gran conflicto es el concepto central que brinda coherencia a todas las enseñanzas bíblicas".

${ }^{4} \mathrm{El}$ presente artículo no trata el tema del gran conflicto entre Cristo y Satanás desde las populares expresiones teológicas de "guerra espiritual", "guerra cósmica", "controversia", "gran batalla", "demonología" u otros términos que destacan la lucha de la iglesia contra los los espíritus demoniacos que ejercen poderes sobre diferentes regiones o territorios (un barrio, una ciudad, una nación). Para más detalles de estos conceptos y otros más, véase Peter Wagner, Oración de guerra (Miami: Editorial Caribe, 1996). ídem, Confrontemos las potestades (Miami: Editorial Caribe, 1997). ídem, Oremos con poder (Miami: Editorial Caribe, 1998). Para un excelente acercamiento y sugerencia para abordar la realidad de estas cuestiones véase el estudio de Esteban Voth, en “La guerra espiritual: ¿Realidad o ciencia-ficción?”, Kairós 30 (Ene.-Jun., 2002): 7-32.

${ }^{5}$ Asociación Ministerial de los Adventistas del Séptimo Día, "El gran conflicto", en Creencias de los Adventistas del Séptimo Día (Buenos Aires: ACES, 2007), 109-117. Para un panorama detallado del gran conflicto como cosmovisión en la teología adventista véase Norman Gulley, 
El conflicto comenzó inexplicablemente en el cielo tras la rebelión de Lucifer y sus ángeles contra el gobierno de Dios (Is 14:12-19; Ez 28:11-19). ${ }^{6}$ En esta rebelión contra el Creador, este ángel llegó a ser Satanás, el enemigo de Dios. Tras una batalla celestial fue expulsado a la tierra junto a sus ángeles (2 Pe 2:4; Jud 6; Ap 12:3-4, 7-9). Este rebelde siempre presentó un deseo constante de entronización al trono celestial. Él es llamado "príncipe de este mundo" (Jn 14:30; 16:11 cf. 1 Jn 5:19) y "el dios de esta era" (2 Co 4:4). En la tierra, Jehová creo con perfección al hombre, la mujer y todo su entorno (Gn 1-2). Ellos reflejaban su carácter santo e inmaculado. La pareja del Edén, con libertad de elección, habiendo sido siendo engañados por Satanás decidieron ser parte de la rebelión contra el Creador al desconfiar de su Palabra. De esta forma, el pecado afectó rápidamente a toda la familia humana. Con la entrada del pecado, Dios se ha visto envuelto en un conflicto constante contra Satanás, el mal, el pecado y la muerte. El enemigo de Dios se encarga desde entonces de actuar contra la humanidad acusando (Job 1:6-9; Zac 3:1; Ap 12:10), tentando (2 Cro 21:1; Mt 4:112; 1 Tes 3:5; 1 Ti 3:7), afligiendo (Job 1:12-18; 2:6-7; Lc 13:16; Ap 2:10), esclavizando (Hch 10:38; Ef 6:16; 2 Ti 2:26), engañando (Gn 3:1-13; 2 Co 2:11; 4:4; 11:13-15; 2 Ts 2:9-10; 1 Jn 4:1-4) y destruyendo (Jn 10:10; 1 Pe 5:8). De este modo, según Frank Holbrook, son cuatro los objetivos por parte de Dios en este conflicto: ${ }^{7}$

1. Vindicar su carácter, la ley y su gobierno de toda acusación.

2. Asegurar y reafirmar la lealtad de su creación inteligente sin pecado.

3. Efectuar la salvación de todos los humanos pecadores que pueden responder a la invitación celestial a aceptar el señorío del Creador.

4. Destruir a Satanás, los ángeles y los pecadores impenitentes, y erradicar los efectos del pecado para restaurar la condición original de la tierra y el universo.

Systematic Theology. Prolegomena (Barrien Springs, MI: Andrews University Press, 2003), 416-453; ídem, "The Cosmic Controversy: World View for Theology and Life", JATS 7, no. 2 (1996): 89. Lichtenwalter, "Worldview Transformation and Mission: Narrative, Theology, and Ritual in John's Apocalypse", 211-244. Douglass, "The Great Controversy Theme: What it means to Adventists", 5-7. Frank Holbrook, "El gran conflicto", en Tratado de teología Adventista del Séptimo Día, 980-1009. Fernando Canale, "La cosmovisión teológica y su influencia sobre la Iglesia Adventista del Séptimo Día", en Mensaje, misión y unidad de la iglesia (Buenos Aires: ACES, 2015), 101-122.

6José María Bertolucci, "The Son of the Morning and the Guardian Cherub in the Context of the Controversy Between Good and Evil" (Tesis doctoral, Andrews University, 1985), 146- 296.

"Estos cuatro objetivos han sido señalados por Holbrook en "El gran conflicto", 980. 
Así, el universo, y en especial el planeta tierra con todos sus habitantes, están envueltos en un conflicto de obediencia y lealtad al Creador. De esta manera, la misión tiene razón de ser dentro de este conflicto cósmico. Dios busca restablecer la verdadera comunión con el hombre caído para su salvación plena. Por esta razón, Cristo, con su muerte y resurrección, ha ganado la victoria definitiva de este problema (Gn 3:15; Mt 28:18; Ro 8:28-37; 16:20; Col 2:13-15; Hb 2:14; Ap 12:9, 10), el cual se consumará con el establecimiento de su reino luego del milenio (Ap 21-22).

\section{LA MISIÓN DESDE LA COSMOVISIÓN DEL GRAN CONFLICTO}

Para continuar, es provechoso responder ¿Qué es la misión? Jiří Moskala declara que es "hacer todo lo posible para comunicar el mensaje de salvación al mundo" .8 Por su parte, Eckhard Schnabel señala que "es la creación de una comunidad de discípulos". 9 El destacado misionologo Donald MacGavran destaca que "es una empresa dedicada a proclamar las buenas nuevas de Jesucristo, y a persuadir hombres y mujeres para que lleguen a ser sus discípulos y miembros responsables de su iglesia". ${ }^{10}$ En Reglamentos eclesiásticoadministrativos de la División Sudamericana, se alega que "la misión de la IASD es llamar a todas las personas a que sean discípulos de Jesucristo, proclamar el evangelio eterno en el contexto de los mensajes de los tres ángeles (Ap 14:6-12), y preparar al mundo para el pronto regreso de Cristo" ${ }^{11}$ De esta pertinente declaración se puede vislumbrar un enfoque misionológico dentro de la perspectiva del gran conflicto que se ampliará a continuación.

61.

8Jiří Moskala, "Misión en el Antiguo Testamento", en Mensaje, misión y unidad de la iglesia,

${ }^{9}$ Eckhard J. Schnabel, Early Christian Mission (Downers Grove, IL: InterVarsity, 2004) 1:356.

${ }^{10}$ Donald A. McGavran, Understanding Church Growth (Grand Rapids, MI: Eerdmans, 1990), 23-24. Anteriormente él afirmó lo siguiente: “Misión, definida como el programa de Dios para los hombres, es obviamente un asunto con muchos aspectos. Cada aspecto puede ser llamado misión. ¿Ha asignado Dios alguna prioridad entre estas miríadas de buenas actividades? [...] La principal e irremplazable propósito de la misión es el crecimiento de la iglesia". McGavran, Understanding Church Growth, 20, 22.

${ }^{11}$ Iglesia Adventista del Séptimo Día y Secretaría de la División Sudamericana, Reglamentos eclesiástico-administrativos. 3ra ed. (Buenos Aires: Asociación Casa Editora Sudamericana, 2018), 66. 


\section{LA DEIDAD CONDUCE LA MISIÓN \\ EN MEDIO DEL GRAN CONFLICTO}

\section{Dios en su misión}

Con la entrada del pecado, Dios es el primero en proclamarle al pecador la esperanza de salvación (Gn 3:15, 21). A partir de allí, toda la Biblia lo presenta auto revelándose para redimir a la humanidad (Dt 29:29; 1 S 3:21; Dn 2:22, 27; Ef 3:3-5). Dentro del contexto del conflicto, él actúa para demostrar su carácter justo frente a las acusaciones de Satanás. ${ }^{12}$ Por este motivo, un instrumento para manifestar su justicia y misericordia a Israel y las naciones fue el tabernáculo/templo. ${ }^{13}$ Desde allí, a través de sus mobiliarios, el sacerdocio y servicios diarios y anuales demostraban que el pecado no tiene parte en su gobierno. ${ }^{14}$

Los oráculos del Antiguo Testamento (AT) habían proclamado que Jehová enviaría a su Siervo con una misión definida (Is 42:1-9; 49:1-7; 50:4-9; 52:13-53:12; 61:1-3). En el Nuevo Testamento (NT), Jesús es el enviado de Dios (Jn 17:18; 20:21) para revelar su carácter a los hombres (Jn 1:18; 3:16; 14:9; Heb 1:1-3), redimir al pecador (1 Ti 1:15) y vencer al imperio de Satanás (Heb 2:14). En sus mensajes, el Padre es el mayor interesado salvar al hombre (Mt 6:8, 14-15, 23; 7:11; 10:29; Mr 11:27; Lc 15:11-24; Jn 6:32; cf. Ro 8:17; 1 Jn 3:1-2)

\section{El ministerio de Jesús, la misión y el gran conflicto}

Jesús, el enviado de Dios afirmó que vino " para servir y para dar su vida en rescate por muchos" (Mr 10:43-45 cf. Mr 14:24, 27; Jn 1:29; 10:11, 15, 17). Por tal razón, la instauración de su reino es evidente en los cuatro evangelios como parte trascendente de su obra salvífica. ${ }^{15} \mathrm{Su}$ vida estuvo centrada en la misión a través de sus enseñanzas, milagros, sanidades, colocando al hombre en armonía con Dios. Su sacrificio evidenció el amor y la justicia divina. La cruz expresó el

${ }^{12}$ Gulley, Systematic theology, 442.

${ }^{13 R a u ́ l ~ Q u i r o g a, ~ " E l ~ c i ́ r c u l o ~ m i s i o n a l ~ d e ~ I s r a e l ~ a ~ p a r t i r ~ d e l ~ s a n t u a r i o ", ~ D a v a r L o g o s ~ 8, ~ n o . ~} 2$ (2009): 185-190. Jack F. Blanco, "The Sanctuary and the Mission of the Church," JATS 9, no. 1-2 (1998): 243-259.

${ }^{14}$ Christian Varela, "Ecos temáticos y teológicos del Día de Expiación en el libro de Apocalipsis", en "La palabra que Yo te diga, esa hablarás": Estudios selectos en el Pentateuco. Ed. Merling Alomía (Lima, Perú: Ediciones Theologika - Universidad Peruana Unión, 2017), 187-218. ${ }^{15}$ Clinton Wahlen, "Misión en el Nuevo Testamento", 82. 
verdadero carácter de Dios frente al pecado y el mal, trascendiendo los límites de la experiencia humana, siendo una teodicea cósmica frente al gran conflicto (Fil 2:5-11). ${ }^{16}$ Durante su ministerio terrenal para vindicar el carácter del Padre se enfrentó en reiteradas ocasiones con los demonios (Mt 12: 46; Mc 1:22-23; 5:1-27; 9:17-18; Lc 4:24; 8:2; 11:26; etc.), suplió las necesidades de los hombres (Mt 15:2128; Mc 1: 21-28; Lc 7: 1-10; 9:37; etc.) y enseñó pública y personalmente (Mt 5-7; Lc 12; Jn 3-4; etc.). Luego de su resurrección, bajo una nueva autoridad recibida envía a sus discípulos a hacer más discípulos, ${ }^{17}$ dejando la promesa de su presencia continua en medio del conflicto (Mt 28:18-20).

\section{La obra del Espíritu Santo, el gran conflicto y la misión}

La misión en el contexto del conflicto es impensable realizarla sin la presencia del Espíritu Santo. Él se encargó de fortalecer, sustentar y dirigir la misión de Noé (Gn 6:3, 5), Josué (Éx 31:3), Otoniel (Jue 3:10), Gedeón (Jue 6:34), Jefté (11:29), Sansón (13:25), David (1 S 16:13) y los profetas (Ez 11:5). También guió el ministerio de Cristo (Lc 3:22; 4:1, 17-19; Hch 1:2; 20:38). Antes de su partida, Jesús realizó la promesa del Espíritu a sus discípulos (Jn 14:26; 15:26; 16:7), brindándoles la seguridad de su presencia para la transformación del carácter (Jn 3:3-5; 16: 8-15; 1 Co 6:11; 1 Pe 1:2; Tito 3:5; 1 Tes 5.23; Gá 5:25-26; Hb 9:14) y ser testigos hasta lo último de la tierra (Lc 24:49; Hch 1:5, 8).

Luego de su ascensión y entronización esta recepción se hace evidente en el Pentecostés (Hch 2 cf. Ap 1:4; 4:5-6). Allí facilitó la comunicación del evangelio otorgándoles el don de lenguas a los discípulos (Hch 2:4). De este modo, él otorga dones espirituales para el crecimiento integral de la iglesia con fines de proclamación y edificación de los creyentes (Hch 2:38; Ro 12:6-8; Ef 4:12; 1 Co 12).

En la misión apostólica registrada en los Hechos, el Espíritu Santo llenó a los discípulos para el cumplimiento de la misión (4:31), eligió a Pablo y Bernabé para la primera obra transcultural y los dirigió (13:1-4). Él prohibió la predicación en Asia y Bitinia, conduciéndolos a Macedonia para cumplir allí su tarea (16:6-

16Gulley, 443.

${ }^{17}$ Carmelo Martines, "La metodología de la misión a partir de los textos de la misión", DavarLogos 8, no. 2 (2009): 148. 
10). Es él quien confirma visiblemente a los judíos la inclusión de los gentiles como hijos de Dios (Hch 10).

En conclusión, la Deidad busca restaurar la relación con el pecador. Por esta razón, su misión tiene que ver con la proclamación de un mensaje y lograr restablecer una comunión permanente con la humanidad.

\section{LA DEIDAD INVITA AL HOMBRE A SER MISIONERO}

Dios es el origen y motivación de la acción misionera. Por eso, Él invita al hombre a ser un participante activo en su plan de restaurar al hombre a su imagen. Él eligió a los patriarcas, jueces, profetas, reyes y diversos pueblos extranjeros para realizar su obra. Tal como lo afirma Moskala, "la elección divina es inseparable de la misión."18 El principal cometido de Israel era presentar un ejemplo a las naciones que las lleve a reconocer la gloria de Dios y servirle (J1 2:914; Is 19:23-25; 61:9-11; Ez 20:12; 36:23; 38:23; 39:7, 27-29).

En el NT, Jesús restauró el entendimiento de la misión que Israel había distorsionado y la transmitió a sus discípulos. Él los envía a hacer más discípulos (Mt 28:18), invitándolos a ser "pescadores de hombres" (Lc 5:10; 1:17). ${ }^{19}$ De esta manera, como el Padre lo envió, él también los envía (Jn 20:21). Por esta razón, cada discípulo debe ser un imitador de él. Así, es ineludible la participación de los creyentes en la misión hasta el tiempo del fin (Ap 14:6-13). ${ }^{20}$ Es una necesidad inherente del cristiano testificar sobre su propia experiencia salvífica (Hch 4:20; Ro 1:14-17; 1 Co 9:16).

\section{LA MISIÓN DE LA IGLESIA Y LOS ATAQUES DE SATANÁS}

En el gran conflicto, Satanás es presentado como un ser real que se opone a la misión de Dios y su pueblo. En el AT, su presencia no es claramente visible, pero actuó de diversas maneras para impedir los planes divinos. La proclamación del nombre de Dios comienza con Set y su familia, pero se ve obstaculizada cuando comienzan a familiarizarse con la descendencia de Caín (Gn 4:26; 6:1). La misión se vio casi anulada a no ser por Noé y su familia (6:1-8).

${ }^{18}$ Moskala, 63.

19 Wahlen, 83.

20 Para un estudio detallado de la misión en el Apocalipsis véase Ekkehardt Mueller, "La misión en el Apocalipsis", en Mensaje, misión y unidad de la iglesia, 125-148. 
Los descendientes de Jacob fueron esclavizados, pero Dios se encargó de liberarlos. Luego de continuos conflictos en el desierto durante el peregrinaje a Canaán, el pueblo siempre contó con la misericordia de divina para no ser destruido. En la historia de Israel, la desobediencia constante a los mandamientos divinos fue el principal impedimento para que los reyes, sacerdotes, profetas y el pueblo cumplan con su cometido divino. Aunque castigados con el exilio, los planes de Dios igual se realizaron.

Durante el ministerio de Jesús, Satanás buscó impedir continuamente el cumplimiento de su obra mesiánica. Desde su nacimiento (Mt 2:13-20; Ap 12:2, 3, 5), las tentaciones en el desierto (Mt 4:1-11), enfrentamientos continuos con demonios (Mr 5.1-20; Lc 8.26-39), el hostigamiento de los líderes religiosos (Mt 12:24; 23; 26:1-5), la incomprensión de algunos discípulos (Mt 16:23) y su ejecución en la cruz (27:41-44) evidencian las acciones de Satanás para obstaculizar su misión. Sin embargo, este siempre fue derrotado.

En los tiempos apostólicos, el enemigo de Dios utilizó diferentes medios para estorbar la obra de los discípulos. Las persecuciones por parte de los dirigentes judíos (Hch 4:1-22; 5:17-32; 8:2-3), los graves problemas sociales (Hch 6:1-7; Sant 5:1-5), morales (1 Co 5:1-3; 6:9-20; 7) y teológicos (Hch 15; Corintios $12-$ 15; Gá 3-4) fueron los medios utilizados por el diablo para impedir el cometido de los creyentes. ${ }^{21} \mathrm{El}$ mismo Pablo afirmó: "por lo cual quisimos ir a vosotros, yo Pablo ciertamente una y otra vez, pero Satanás nos estorbó" (1 Ts 2:18). Sin embargo, ante cada dificultad, la misión cobro nuevas fuerzas, viéndose como Dios tomó las adversidades para la expansión de su reino.

En el tiempo final, el conflicto que enfrentará el remanente para cumplir su misión mundial se verá afectado por los aliados del dragón (12:17-13:17). Sin embargo, en aquel tiempo Cristo dará la victoria final a su pueblo (Dn 12:2; Ap 14:1$5)$.

En conclusión, la misión siempre tuvo dificultades no fáciles de resolver, pero Dios se encargó en todo momento de utilizar esos problemas para bendición de su obra.

${ }^{21}$ La circuncisión y el concilio de Jerusalén (Hch 15:1, 5; cf. 11:2; Gá 2:12) 


\section{LA MISIÓN CONSISTE EN LLEGAR A TODO EL MUNDO}

Toda la humanidad está envuelta en el conflicto a causa del pecado (Ro 5:12). Por esta razón, la misión se extiende a ofrecer la salvación a todo habitante del mundo.

Noé fue llamado a pregonar un mensaje mundial (2 Pe 2:5). Abraham habría de ser de bendición para todas las familias de la tierra (Gn 12:3; 18:18; 22:18)22 como también Isaac (Gn 26:4) y Jacob (Gn 13-15; 35:11,12; 46:3). ${ }^{23}$ Israel debía ser obediente al pacto (Dt 4:5-8; 10:17-19; 29:24-26; 3112-13) y así reflejar la gloria divina a las naciones (Éx 19:5-6; Dt 4:6; 26:18, 19; Jos 2:8-11; 2 Cro 2:11-12; 1 R 10:19; 2 Cro 9:1-8; Is 42:6; 58:8; 60:1-3; 62:1-2; Ez 36:23). Moskala afirma que el "propósito de Dios era bendecir a todas las naciones por medio de Israel". ${ }^{24} \mathrm{El}$ plan misional de Dios en el AT nunca estuvo centrado únicamente en Israel. Su ubicación geográfica ayudaba al cumplimiento de la misión, ya que confluían los caminos que venían del Norte (Europa y Asia) hacia el Sur (África). ${ }^{25}$ El Templo sería llamado “casa de Dios para todos los pueblos" (Is 56:6,7) revelando así su sentido mundial. En este contexto, se pueden destacar los ejemplos misionales de testificación activa de diferentes personajes que llevaron el conocimiento de Jehová a las naciones: ${ }^{26}$ José en Egipto (Gn 45:5-8; 50:19-21), Elías en Sidón (1 R 17:9-24) y Jonás en Nínive. Los Salmos también reflejan la proclamación del mensaje divino a las naciones $(57: 9 ; 117: 1 ; 67 ; 86: 9-10 ; 96: 2-9 ; 105: 1-2 ; 108: 3 ; 126: 2-$ 3; 145:11, 12, 21). Al mismo tiempo, en el cautiverio también los propósitos misioneros fueron llevados como en los casos de Daniel en Babilonia, Ester, Esdras y Nehemías con los persas. ${ }^{27}$

El NT presenta el cumplimiento de la misión transcultural de una manera distintiva. Jesús reiteró la importancia de llegar a todas las naciones (Mt 24:14; 28:19; Mc 16:15). En Hechos, antes del ascenso de Jesús, deja la comisión desde un punto de partida local para convertirse en mundial (Lc 24:47; Hch 1:8). El reino

22M. Daniel Carroll R. “Blessing the Nations: Toward a Biblical Theology of Mission from Genesis", Bulletin for Biblical Research 10, no. 1 (2000) 17-34.

${ }^{23}$ Daniel Rode,

${ }^{24}$ Moskala, 67.

${ }^{25}$ Lewis, Misión mundial. Las bases bíblicas e históricas, 40.

26.Moskala, 67-70.

27Lewis, Misión mundial. Las bases bíblicas e históricas, 51-52. 
de Dios debía extenderse a todas las naciones. Pablo fue llamado a predicar a los gentiles (Gá 3:6-9; Ef 3:6-12) y llegar a todo el mundo (Ro 15:19-24; Col 1:23). Pedro destaca que los cristianos son un reino de sacerdotes para anunciar a toda la extensión geográfica (1 Pe 2:9). En el Apocalipsis, enfatiza la expresión nación, tribu, lengua y pueblo como campo de acción de la obra de Dios (5:9; 7:9; 10:11; $11: 9 ; 13: 7 ; 14: 6 ; 17: 15)$.

En conclusión, la misión en el gran conflicto abarca a toda la tierra, y los creyentes deben llevar el evangelio a toda persona.

\section{LA MISIÓN Y EL MENSAJE}

$\mathrm{Al}$ analizar la misión, es indispensable tratar el tema del mensaje, ya que ambos son inseparables. Diversos personajes elegidos por Dios como también su pueblo, a través de toda la historia de la salvación tuvieron un mensaje distintivo. En la gran comisión, Jesús hizo evidente la importancia del mensaje a través de los verbos empleados tales como "predicar", "anunciar" (Mr 16:15; Lc 24:47) y “enseñar" (Mt 28:20). ${ }^{28}$ ¿Cuál es el mensaje de la iglesia que tiene anunciar en el cumplimiento de su misión?

\section{La centralidad de Cristo}

El evangelio de Marcos al igual que el de Pablo y el mensaje del primer ángel de Apocalipsis 14, evidencian la centralidad de Jesús (Mr 16:15; 1 Cor 2:2; Ap 14:6; cf. 1:5; 3:9, 19). Su sacrificio expiatorio y sustitutivo revelan el amor y la justicia de Dios (Ef 2.5-10; Ro 3.21-26; Heb 8-7-12; 2 P 1.3-4; 2 Co 5.15-17; Ti 3.3-7). Esta proclamación confirma los anuncios realizados por los profetas del AT (Gn 3.15; Sal 2; 22; 110; Is 7:14; 9:6; 11.1-9; 52:13-53:12; Miq 5:2; Jer 23:5-6; Hag 2:7; Mal 3:1; 4:2; cf. Heb 1:1-2). Sin embargo, el mensaje de la salvación no concluye con la cruz, sino que se complementa con el anuncio de la intercesión de Jesús en santuario celestial (Heb 8:1-5; Ap 4-5; 8:1-5) y su pronto regreso. ${ }^{29}$

\section{Arrepentimiento y conversión}

28 Martines, 150.

${ }^{29}$ Christian Varela, "Hacia una soteriología en el libro de Apocalipsis", Evangelio 10 (2017): 148-154, 161-162. 
El arrepentimiento es el reconocimiento de la culpabilidad, y es indispensable para la salvación. Dios utilizó a los profetas para llamar a Israel como a Judá con el mensaje de arrepentimiento (2 Re 17:13; Jer 3:22; 4:1; 31:18-20; Os 14:1; Is 44:22; Ez 14:6; J1 2:12-13; Mal 3:7). Ellos también dieron un mensaje de juicio contra las naciones para llamarlas a la conversión. Tales son los casos de Jonás, Isaías (13-19), Ezequiel (25: 15-17; 9:1-11; 18:30), Jeremías (46-51), Daniel (Dn 4:27), Amos (1:3-5; 1:6-8; 2.1-3), Habacuc (2:6-17) y otros. ${ }^{30}$

El mensaje de Jesús inició con la invitación al arrepentimiento (Mt 4:17; 11:20; Mar 1:15; Luc 13:3, 5; 15:7, 10). Los apóstoles fueron comisionados en su primera misión a predicarlo (Mc 6:12). Luego, Pedro y Pablo también lo hicieron desde sus inicios (Hch 2:38; 3:19; 8:22; 17:30; 26:20). En el Apocalipsis se evidencia la importancia de arrepentirse mientras Dios concede la oportunidad de una conversión real $(2: 5,16,22 ; 3: 3,9,16 ; 9: 20-21)$.

\section{La centralidad de la Palabra de Dios}

Cuando Dios escogió a los hombres para una misión, ellos anunciaron la Palabra de Dios. Se podría destacar a Moisés (Éx 3:15; 4:28; 24:3-4; Nm 11:24), Josué (3:9), profetas tales como Samuel (1 S 8:10; 15:1), Semaías (2 Cro 11:4), Isaías (20:2), Jeremías $(34: 4,6,8,11 ; 37: 2 ; 50: 1)$, Oseas (1:1-2), Hageo (1:2-3; 2:1); Jonás (3:23 cf. 2 R 14:25), Ezequiel (38:17), Amos (8:11) y mucho otros. Así, la Palabra divina era relevante en su misión para anunciar, exhortar y animar a sus oyentes.

El Nuevo Testamento también presenta la centralidad de la Palabra de Dios por parte de los misioneros. Jesús la proclamaba (Lc 5:1) colocándola por encima de las tradiciones judías (Mt 15:6; Mr 7:13). Ella sería el medio de santificación de los creyentes (Jn 17:17). Los discípulos igualmente lo hicieron (Hch 4:31; 6:2; 13:25, 46; Col 1:25; Heb 13:7; Ap 1:2, 9). Según el Apocalipsis, los mártires de todos los tiempos dieron sus vidas como testimonio de ella (6:9, 20:4). Por tal razón, la misma debe ser la única regla de fe y práctica de los creyentes y su mensaje a proclamar.

${ }^{30}$ Los oráculos divinos fueron contra Judá, Israel, Egipto, Babilonia, Filistea, Moab, Damasco, Nínive, Amon, Tiro y Edom. 


\section{Las verdades distintivas del remanente}

Tras los engaños pronunciados por Satanás es necesaria la verdad acerca de Dios, Cristo y Satanás. ${ }^{31}$ Como fue afirmando anteriormente, la obra del Espíritu es fundamental en el proceso de guiar al pecador a estas verdades (Jn 14:17; 15:26; $16: 7,13)$.

Por tal motivo, en el AT, tal como lo afirma Moskala, es evidente que "los profetas hablaron constantemente contra los falsos sistemas de religión y amonestaron contra la infiltración del paganismo dentro del culto verdadero" ${ }^{32}$ Esto implicaba la adoración al verdadero Creador (Gn 1:1; 14:19-22; Dt 32:6; S1 8; 19; 33:9; 104; 139; Isa 40:28; 41:20; 45:7-8; 46:9-10; 55:11; Jer 10:6-16; 51:15-19), su único lugar culto (Éx 25:8; 40:34-35; 2 Cro 7:1-3; Isa 6:1-4) y el exclusivo día de descanso (Éx 20:8-11; Ez 20:20).

Jesús destacó que Satanás es padre de mentira (Jn 8:44). Él mismo es la Verdad (Jn 14:6 Cf. 1:14, 17) y fue reconocido como maestro de la verdad de Dios (Mt 22:16; Mr 12:14). Por esta razón, el pecador necesita de la verdad para la liberación de los engaños de Satanás (Jn 8:44). Pablo por su parte afirmaba predicarla (Ro 9:1; 2 Co 4:2; 7:14; 11:10; Ef 1:13; 1 Ti 2:7) y destacó a la iglesia como el fundamento de ella (1 Ti 3:15). En el Apocalipsis, el remanente que posee la verdad de la Palabra de Dios $(19: 9 ; 21: 5 ; 22: 6)$ se opone a los últimos engaños de Satanás y sus aliados $(12.9 ; 20: 3,10)$, los falsos profetas $(2: 20 ; 19: 20)$ y la mayoría de los habitantes de la tierra engañados (13:14; 18:23; 20:8).

La IASD bajo la interpretación de sola y tota Scriptura, puede afirmar que las verdades olvidadas por los cristianos para estos tiempos finales son el sábado bíblico, el ministerio de Cristo en el santuario celestial, el juicio investigador iniciado en 1844, el mensaje de los 3 ángeles, la reforma pro salud, la vigencia de los diez mandamientos, la verdadera adoración, la caída de Babilonia y la inmortalidad condicional del alma. Por esta razón, debe anunciar estas verdades a un mundo sujeto a los errores de Satanás. A continuación, brevemente se 
expondrán dos de las verdades fundamentales proclamadas por el remanente de todos los tiempos.

\section{El mensaje del juicio}

El mensaje del evangelio trae consigo un mensaje del juicio divino. ${ }^{33}$ Varios escritores bíblicos profetizaron sobre el juicio escatológico, entre ellos Joel (3:12), Oseas (1:8; 2:23), Amos (5:18-20), Isaías (6:1-13; 26:9-11), Jeremías (11:20), Ezequiel (7:3-4; 9:1-11; 18:30), Job (19:25, 29), David (Sal 50:6; 96:13) y Salomón (Ecl 12:13$14)$.

En el NT este tema no es ajeno al mensaje evangélico. Jesús lo advirtió (Mt 10:15; 11:22, 24; 12:36, 41; 16:27; 25:31-46; Lc 11:31; Jn 5:22, 27) al igual que Pablo (Hch 17:30; 24.25; Ro 2:16; 14:10; 2 Cor 5:10; 2 Tim 4:1-2, 8; 1 Ti 5.24; Heb 9.27; 10:27), Pedro (2 P 2:4, 9, 11; 3:7), Juan (1 Jn 4:17) y Judas (1:6, 15). En el Apocalipsis es de suma importancia ya que es vindicado el carácter de Dios antes del regreso del Señor (Ap 6:10; 11:1, 19; 14-6-11; 15:5-8). ${ }^{34}$

\section{El día del Señor}

El mensaje escatológico del establecimiento del reino de Dios en la venida del día del Señor es de gran valor a través de toda la Escritura. Craig Ott, Stephen J. Strauss y Timothy C. Tennent afirmaron que "la escatología es una de las más fuertes motivaciones para la misión". ${ }^{35}$ Los mensajes del AT proclamaron el día de Jehová (Sal 24:7; 47:7, 9; Is 24:27; 65-66; Ez 38-48; Dn 2:34-35, 44; 7:27). Jesús lo afirmó en reiteradas ocasiones (Mt 24-25; Mr 13; Lc 21; Jn 14.1-3; Hch 1:9-11) y lo confirmaron los discípulos (Ro 14:10; 1 Co 16:22; 2 Co 5:10; 1 Ti 2:13; 1 Ts 4:13-18; 2 Ts 1.7-10; 1 P 1:3-5; 2 P 3; etc.). La venida de Cristo es clímax final del Apocalipsis $(1: 7 ; 2: 5,16,25 ; 3: 3,11 ; 6: 14-17 ; 7: 4-16 ; 11: 15-18 ; 21-22)$.

33Jirí Moskala, "The Gospel According to God's Judgment: Judgment as Salvation", JATS 22, no. 1 (2011):28-49; ídem, “Toward a Biblical Theology of God's Judgment: A Celebration of the Cross in Seven Phases of Divine Universal Judgment (An Overview of a TheocentricChristocentric Approach)", JATS 15, no. 1 (2004): 138-165.

${ }^{34}$ Véase Christian Varela, "Ecos temáticos y teológicos del Día de Expiación en el libro de Apocalipsis", en "La palabra que Yo te diga, esa hablarás": Estudios selectos en el Pentateuco. Ed. Merling Alomía (Lima, Perú: Ediciones Theologika - Universidad Peruana Unión, 2017), 187-218. ${ }^{35} \mathrm{Craig}$ Ott, Stephen J. Strauss, and Timothy C. Tennent, Encountering Theology of Mission:

Biblical Foundations, Historical Developments, and Contemporary Issues (Grand Rapids, MI: Baker, 2010), 186. 
Finalmente, se puede afirmar que no hay misión sin mensaje. Los discípulos tienen una verdad presente que proclamar en el tiempo del fin. El remanente debe anunciar la hora del juicio y el pronto regreso de Jesús.

\section{HACIA UNA IGLESIA MISIONERA EN EL MARCO DEL GRAN CONFLICTO}

Luego de trazar algunos aspectos relevantes de la teología de la misión desde la cosmovisión del gran conflicto, se brindarán algunas implicaciones misionológicas para la praxis de las iglesias.

\section{Líderes dispuestos a enfrentar el gran conflicto}

El liderazgo es un factor decisivo en el desarrollo de la misión. Dios llamó a los patriarcas, profetas, sacerdotes y reyes como líderes para llevar al pueblo a una experiencia de santidad, servicio y proclamación en medio del conflicto. La iglesia necesita líderes espirituales capaces de ser ejemplo e incentivar la comunión, relacionamiento y misión en el proceso de discipulado.

\section{Una iglesia ocupada en el ser y el hacer}

La iglesia debe ser equilibrada en los énfasis centrípetos y centrifugos de la misión. La consagración y santidad del cristiano son fundamentales para ser un testigo de Cristo en la vivencia diaria. Norman Gulley afirma que "la iglesia llega a ser un testigo al universo del tipo de Dios al que sirve". ${ }^{36}$ Para ello es necesaria la obra del Espíritu Santo en la transformación del creyente. Al mismo tiempo, el ser testigo implica acciones e intencionalidad en la proclamación para alcanzar a los pecadores.

\section{Una misión transcultural}

El escenario global muestra más de un tercio de la población mundial no cristiana que debe ser alcanzada con la verdad presente. Este desafío conlleva una preparación de misioneros adventistas transculturales de corto y largo plazo. La IASD debe capacitar, motivar, equipar y sustentar misioneros que afronten las

\footnotetext{
${ }^{36}$ Gulley, 443.
} 
diversidades teológicas, sociales y culturales en la evangelización de estos lugares no alcanzados.

\section{La unidad en la misión}

Jesús estableció el principio misionero de parejas discipuladoras (Lc 10:1). Los discípulos siguieron este modelo, Pedro y Juan (Hch 3.1; 4:19), Pablo junto a Bernabé, Silas (Silvano), Juan Marcos y Timoteo (1 Co 9:6; Col 4:10; Hch 13:2, 3; 15:40). La iglesia debiera continuar con este método. Al mismo tiempo, el Espíritu otorgó dones espirituales a los creyentes para que obren en la gran diversidad de formas de evangelización. Los lideres deben realizar un plan estratégico para que los miembros empleen sus dones al servicio de la misión.

\section{La caridad en la misión}

El amor es la característica de todo verdadero discípulo de Cristo (Jn 13:35). Por lo tanto, sin realizar asistencialismo, la IASD debería elaborar planes concretos en el tiempo para servir a los necesitados sociales. ${ }^{37}$ Frente a las importantes crisis económicas que están sufriendo los países latinoamericanos, muchas personas están sobrellevando este impacto. Por eso, los discípulos, siendo fieles mayordomos en sus finanzas, podrían ayudar de manera sistemática a las diversas necesidades de la comunidad. Al mismo tiempo, se pueden elaborar servicios médicos (preventivos y curativos) y educativos gratuitos en favor de los carenciados.

\section{Un proceso de discipulado}

La misión tiene como objetivo la conversión más que la información. ${ }^{38}$ Por tal razón, es necesario llevar a las personas a un encuentro personal y permanente con Jesús y sus verdades para la santificación sus vidas. Las iglesias deben elaborar un plan de discipulado para los nuevos conversos. ${ }^{39}$ A las iglesias y sus

${ }^{37}$ Felix H. Cortez, "The Mission-Charity Dilemma: Fresh Perspectives from Paul's Practice", JATS 26, no. 1 (2015): 160-173. Silvia C. Scholtus "Cualidad y estrategia para la difusión del evangelio: La compasión", Estrategias para el cumplimiento de la misión 16, no. 1 (2018): 59-74.

38Lichtenwalter, 213.

${ }^{39}$ Christian Varela, "Discipulado à moda antiga”, Ministério (Sept.- Oct., 2018): 28-30. 
líderes les corresponde crear un ambiente de cuidado y crecimiento continuo en su experiencia cristiana para restaurar la imagen de su Hacedor.

\section{Reavivamiento en la oración}

Cuando los discípulos no pudieron sacar el demonio de un joven, Jesús les afirmó que en este conflicto es fundamental la oración y el ayuno (Mt 17:14-22). Las iglesias misioneras son iglesias que enfatizan la oración para buscar la comunión divina y ser dirigidas con el fin de evangelizar.

\section{El mensaje debe adaptarse sin distorsionarse}

El mensaje debe ser adaptado para alcanzar a las diversas generaciones, pero sin distorsionarse. Los principios establecidos por la Palabra no deben rebajarse.

\section{Ayuda a las misiones extranjeras}

Las iglesias locales deben comprometerse en devolución de diezmos y ofrendas para que las administraciones eclesiásticas distribuyan a las regiones menos favorecidas y la mantención de misioneros en lugares de misión global.

\section{Invitación a salir de Babilonia}

La IASD es el remanente del tiempo del fin. Dios tiene hijos sinceros en otras denominaciones cristianas y religiones. Por tal razón, es imperativa la invitación a salir del engaño de la Babilonia escatológica. La misión de la iglesia es buscar la "mies" (Lc 10:2), las “ovejas en otro redil" (Jn 10:16) para que sean parte del remanente que "guarda los mandamientos de Dios y tienen la fe de Jesús" (Ap $14: 12)$.

\section{CONCLUSIONES}

La razón de ser de la iglesia remanente es cumplir el mandato de ser y hacer discípulos en el contexto del tiempo del fin. El gran conflicto de los siglos iniciado en el cielo está llegando a su fin. El carácter de Dios tergiversado por los engaños de Satanás debe ser desenmascarado a través del testimonio de los discípulos y la verdad presente del evangelio a todo el mundo. Por tal razón, la Trinidad en su plan misionero, invita a los cristianos a ser parte de ella en la restauración de 
los pecadores a la imagen de su Creador y proclamación de las verdades de la Palabra. La IASD tiene mucho para aportar en la misión mundial y es necesario que cada creyente tome el compromiso de ser parte activa en el desenlace de gran conflicto de los siglos. 